row and continuous 5-0 polypropylene sutures in the second row. The cusp competency was assessed by direct visualization using the videoscope $(3.3 \mathrm{~mm}$ in diameter; Olympus, Tokyo, Japan), which was inserted from the left upper pulmonary vein through the mitral valve and into the left ventricle (Figure 1). The left ventricular venting was continued. The tip of the scope is flexible and was set toward the aortic cusp. The aortic root was pressurized using cardioplegic solution, and the prolapse of the right coronary cusp was clearly demonstrated (Video 1). The free margin of the right coronary cusp was plicated at the Arantius node by $7 \mathrm{~mm}$ using 6-0 polypropylene suture. The competency of the aortic cusp was confirmed by the videoscope (Video 2). Next, the coronary and distal anastomoses were done by 5-0 polypropylene. The cardiopulmonary bypass was weaned, and the transesophageal echocardiogram disclosed normal integrity of the aortic root with no aortic regurgitation.

The method for assessing aortic regurgitation after aortic valve repair during cardiac arrest has been investigated. Usually "eye-ball" testing by surgeons is used. Kunihara and colleagues ${ }^{1}$ introduced some scientific measurements of the cusp morphology using a specialized caliper. The water injection test into the open aortic root is not reliable, and an assessment using transesophageal echocardiography necessitates a coronary anastomosis, distal aortic anastomosis, and aortic declamping. Direct visualization of the aortic cusps after aortic valve repair or aortic root replacement using the valve-sparing technique was reported by Ito and colleagues ${ }^{2}$; however, they observed the aortic cusps from the aortotomy. No reports have been published

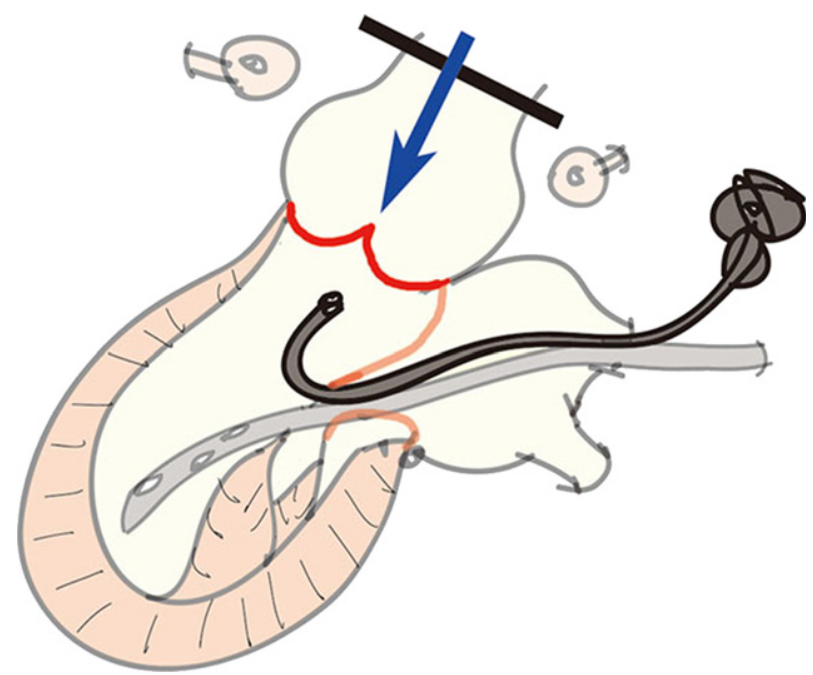

FIGURE 1. The videoscope is inserted from the left upper pulmonary vein through the mitral valve and into the left ventricle.

describing the assessment of the aortic cusps from the left ventricle. The greatest advantage of this method is that direct and instantaneous visualization of valve leakage is possible. The surgeon can then determine the strategy for valve repair according to the video images.

\section{References}

1. Kunihara T, Aicher D, Rodionycheva S, et al. Preoperative aortic root geometry and postoperative cusp configuration primarily determine long-term outcome after valve-preserving aortic root repair. J Thorac Cardiovasc Surg. 2012;143:1389-95.

2. Itoh T, Ohtsubo S, Furukawa K, Norita H. Aortic root endoscopy in valve-sparing operations. J Thorac Cardiovasc Surg. 1997;114:141.

\title{
Perfusion and repair technique in acute aortic dissection with cerebral malperfusion and damage of the innominate artery
}

\author{
Extension of the acute aortic dissection in supra-aortic \\ branches can cause cerebral malperfusion and present \\ a surgical challenge. The innominate artery is, as a first branch \\ From the Departments of Cardiovascular Surgery ${ }^{\mathrm{a}}$ and Radiology, ${ }^{\mathrm{b}}$ Cardiovascular \\ Clinic Bad Neustadt, Bad Neustadt, Germany. \\ Disclosures: Dr Urbanski has a financial relationship with MAQUET Cardiovascular, \\ Inc (La Ciotat, France). Dr Wagner has nothing to disclose with regard to commer- \\ cial support. \\ Received for publication Jan 31, 2012; revisions received April 18, 2012; accepted for \\ publication May 16, 2012; available ahead of print June 18, 2012. \\ Address for reprints: Paul P. Urbanski, MD, PhD, Herz-und Gefaess-Klinik, Salzbur- \\ ger Leite 1, 97616 Bad Neustadt, Germany (E-mail: p.urbanski@ @erzchirurgie.de). \\ J Thorac Cardiovasc Surg 2012;144:982-4 \\ $0022-5223 / \$ 36.00$ \\ Copyright (C) 2012 by The American Association for Thoracic Surgery \\ http://dx.doi.org/10.1016/j.jtcvs.2012.05.042
}

Paul P. Urbanski, MD, PhD, ${ }^{a}$ and Matthias Wagner, MD, ${ }^{\mathrm{b}}$ Bad Neustadt, Germany of the aortic arch, most frequently involved in the dissection, and the short distance to its bifurcation can occasionally cause complex pathology, which can lead to real anastomosis problems during arch repair. In such cases, cannulation of the right carotid artery (RCA) is especially advantageous because it ensures sufficient cerebral perfusion during surgery, and, if the extensive damage of the innominate artery makes direct anastomosis with a vascular prosthesis challenging or even unsuitable, it allows use of the cannulation side-graft for the use of an aorta-carotid bypass.

\section{CLINICAL SUMMARY}

To ensure sufficient cerebral and global perfusion in patients with cerebral malperfusion caused through 

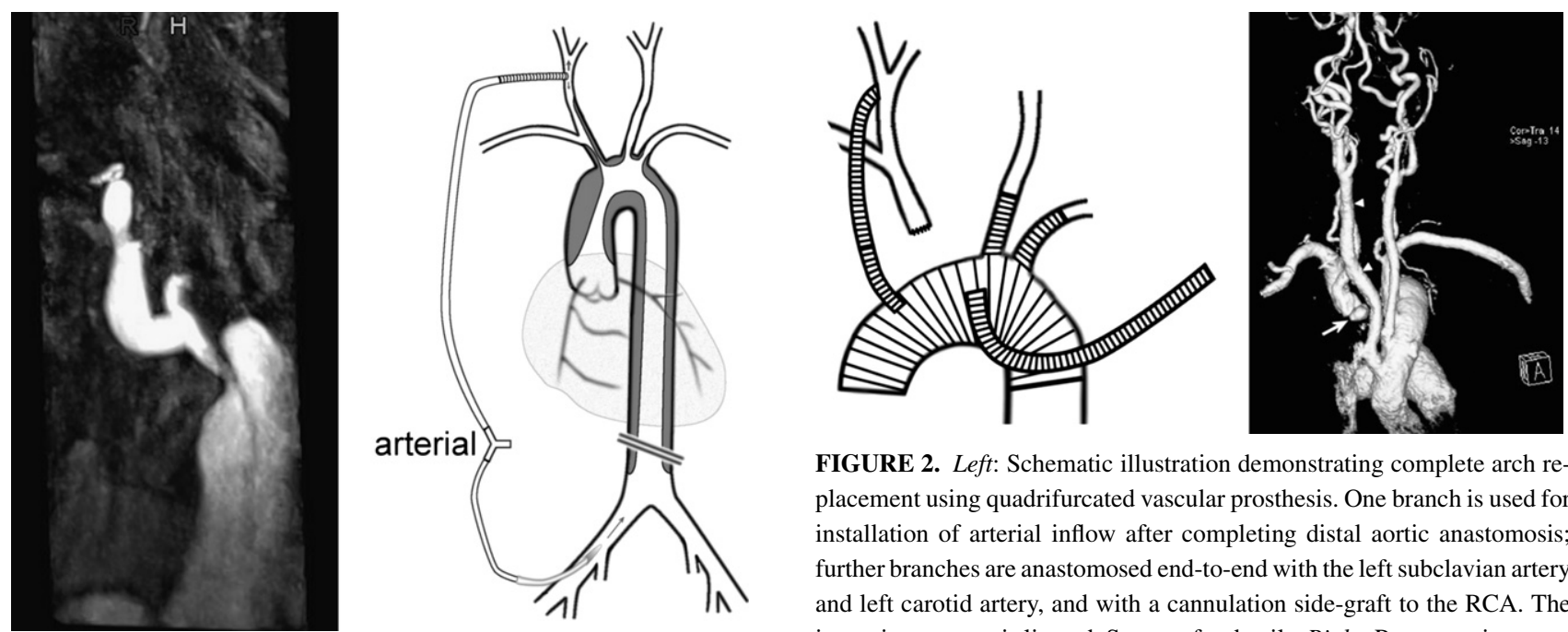

FIGURE 2. Left: Schematic illustration demonstrating complete arch replacement using quadrifurcated vascular prosthesis. One branch is used for installation of arterial inflow after completing distal aortic anastomosis; further branches are anastomosed end-to-end with the left subclavian artery and left carotid artery, and with a cannulation side-graft to the RCA. The innominate artery is ligated. See text for details. Right: Postoperative computed tomographic angiography demonstrating ligated innominate artery (arrow) and right-sided aorta-carotid bypass (arrowheads). obliteration of the true lumen and cerebral malperfusion. Right: Schematic illustration of cannulation and perfusion management during cardiopulmonary bypass. See text for details.

obliteration of a supra-aortic artery, a Y-shaped arterial line is used for arterial inflow from one pump, as described previously. ${ }^{1}$ One line is installed in the femoral artery in the standard manner, and the second line is used for cannulation of the selected carotid artery. The use of separate pumps is not necessary because the peripheral resistance in the arteries cannulated ensures a proper flow distribution. ${ }^{2}$ If a malperfusion is caused by obliteration of the innominate artery, the RCA is cannulated (Figure 1). The RCA is isolated through an approach on the neck along the margin of the sternocleidomastoid muscle. ${ }^{2}$ After crossclamping the RCA, a longitudinal incision is made, and an 8- or 10$\mathrm{mm}$ vascular prosthesis (InterGard, InterVascular; MAQUET Cardiovascular, Inc, La Ciotat, France) is anastomosed end-to-side with a continuous 5.0 Prolene suture. After crossclamping the femoral line and supra-aortic arteries, the flow is reduced to approximately $1.5 \mathrm{~L} / \mathrm{min}$, and an arch repair is performed under mild hypothermic $\left(\sim 32^{\circ} \mathrm{C}\right)$ circulatory arrest and unilateral cerebral perfusion through the RCA with arterial blood temperature at $28^{\circ} \mathrm{C}$. The management of cerebral perfusion and neurovascular monitoring, and the neurologic outcome in patients undergoing operation via this technique have been described extensively. ${ }^{3,4}$ After completing the distal aortic anastomosis, the arterial line from the femoral artery is switched to the side-graft of the aortic arch prosthesis (InterGard Aortic Arch, InterVascular; MAQUET Cardiovascular, Inc), and the perfusion of the lower body is reinstituted. ${ }^{3}$ The left subclavian and left carotid arteries are anastomosed with respective side-grafts of the arch graft, and cerebral perfusion through these vessels is released. If repair or anastomosis of the innominate artery is inappropriate, the side-

graft used for carotid cannulation is disconnected, pulled along the RCA into the chest, and anastomosed with the last side-graft of the arch prosthesis (Figure 2). The damaged innominate artery is then ligated, and the procedure is completed by repairing the proximal aorta.

Between 2001 and 2011, 152 patients underwent aortic surgery for acute type A dissection. Among 12 patients with cerebral malperfusion, 3 presented extensive damage of the innominate artery during surgery, demanding the surgical approach as described. All patients recovered completely after surgery and have not had any neurologic symptoms during the median follow-up time of 44 months (range, 34-46 months).

\section{DISCUSSION}

A safe method to ensure sufficient cerebral perfusion in patients with malperfusion caused by narrowing of the innominate artery is cannulation and perfusion of a supraaortic artery distally of the stenosis. However, because of occlusion of the innominate artery, the perfusion of the lower body through the arterial line installed above the narrowing can be insufficient. Moreover, high resistance at the level of the innominate artery can lead to increased flow and pressure in the brain-supplying arteries and cause overperfusion and neurologic damage regardless if the right carotid or axillary artery is used for cannulation. ${ }^{5}$ Use of a bifurcated line ensures sufficient perfusion of the head and lower body during extracorporeal circulation and simple and adequate cerebral protection during arch repair. ${ }^{1}$ The axillary-femoral inflow, as proposed by others, ${ }^{6}$ is theoretically similar to the carotid-femoral technique presented, but it would not ensure cerebral perfusion if the innominate artery bifurcation or proximal right common carotid artery was involved in the pathology. ${ }^{5}$ Moreover, 
cannulation of the carotid artery can be performed on the right or left side in accordance with vascular pathology. ${ }^{1}$ If the proper flow in the carotid artery cannot be restored by arch repair, which can occur occasionally when the repair of a dissected innominate artery bifurcation is not possible, an aorta-carotid bypass may be necessary and easily performed with a carotid side-graft used for cannulation.

\section{References \\ 1. Urbanski PP. Carotid artery cannulation in acute aortic dissection with malperfu-} sion. J Thorac Cardiovasc Surg. 2006;131:1398-9.
2. Urbanski PP, Lenos A, Lindemann Y, Zacher M, Frank S, Diegeler A. Use of a carotid artery for arterial cannulation: side-related differences. Thorac Cardiovasc Surg. 2010;58:276-9.

3. Urbanski PP, Lenos A, Bougioukakis P, Neophytou I, Zacher M, Diegeler A. Mildto-moderate hypothermia in aortic arch surgery using circulatory arrest: a change of paradigm? Eur J Cardiothorac Surg. 2012;41:185-91.

4. Urbanski PP, Lenos A, Zacher M, Diegeler A. Unilateral cerebral perfusion: right versus left. Eur J Cardiothorac Surg. 2010;37:1322-36.

5. Orihashi K, Sueda T, Okada K, Takahashi S. Compressed true lumen in the innominate artery: a pitfall of right axillary arterial perfusion in acute aortic dissection. J Thorac Cardiovasc Surg. 2009;137:242-3.

6. Minatoya K, Ogino H, Matsuda H, Sasaki H. Rapid and safe establishment of cardiopulmonary bypass in repair of acute aortic dissection: improved results with double cannulation. Interact Cardiovasc Thorac Surg. 2008;7:951-3.

\title{
Lateral caval flap repair of adult sinus venosus atrial septal defect: A natural novel approach
}

\author{
Gurjyot Bajwa, MD, ${ }^{\mathrm{a}}$ Iva Dostanic-Larson, MD, PhD, ${ }^{\mathrm{b}}$ Richard A. Krasuski, MD, ${ }^{\mathrm{c}}$ and \\ Gosta B. Pettersson, MD, PhD, ${ }^{\mathrm{a}}$ Cleveland, Ohio
}

Ten percent of atrial septal defects (ASD) are sinus venosus ASDs associated with partial anomalous pulmonary venous connection, with one or more veins from the right upper lobe entering the lateral aspect of the superior vena cava (SVC). Repair thus involves ASD closure and rerouting of the anomalous pulmonary veins to the left atrium. Surgical repair techniques include single patch, double patch, and Warden procedures, all of which require incisions or suturing in the right atrium that could interfere with the blood supply to the sinus node or directly injure the sinus node and expose the left atrium to a nonendothelialized patch. Although unusual, reported complications include sinus node dysfunction, pulmonary vein obstruction, and baffle thrombosis and embolic events. ${ }^{1-4}$ Owing to ASD location and anomalous veins, device closure is not an option.

We describe a novel approach using the lateral wall of the SVC as a flap to baffle the anomalous veins to the ASD, combined with an autologous pericardial patch to close

From the Department of Thoracic and Cardiovascular Surgery, ${ }^{\mathrm{a}}$ Heart and Vascular Institute; Cleveland Clinic Lerner College of Medicine ${ }^{\mathrm{b}}$; and Department of Cardiovascular Medicine ${ }^{\mathrm{c}}$ Heart and Vascular Institute, Cleveland Clinic, Cleveland, Ohio.

Disclosures: Authors have nothing to disclose with regard to commercial support.

Accepted for Presentation on Demand (POD) electronic presentation at the 92nd Annual Meeting of The American Association for Thoracic Surgery, San Francisco, California, April 28-May 2, 2012.

Received for publication March 20, 2012; revisions received April 25, 2012; accepted for publication May 16, 2012; available ahead of print June 18, 2012.

Address for reprints: Gosta B. Pettersson, MD, PhD, Cleveland Clinic Foundation, 9500 Euclid Ave, Mail Code J-41, Cleveland, OH 44195 (E-mail: petterg@ccf. org).

J Thorac Cardiovasc Surg 2012;144:984-5

$0022-5223 / \$ 36.00$

Copyright (c) 2012 by The American Association for Thoracic Surgery

http://dx.doi.org/10.1016/j.jtcvs.2012.05.048 and augment the lateral SVC defect without exposing the left atrium to a nonendothelialized patch.

\section{PATIENTS AND METHODS}

From January 2000 to June 2010, 32 consecutive patients underwent surgical repair of sinus venosus ASD with anomalous pulmonary veins with lateral caval flap. Mean age was 48 years (range, 26-74 years); 14 were men and 18 women. Available preoperative and postoperative electrocardiograms were reviewed. The Social Security Death Master File was used to assess late mortality, and follow-up was obtained using a questionnaire approved by the Institutional Review Board of the Cleveland Clinic, with mean follow-up of approximately 60 months.

\section{OPERATIVE TECHNIQUE}

Intraoperative transesophageal echocardiography was performed. An upper partial ministernotomy was used for isolated procedures and those combined with patent foramen ovale closure (12 patients), and full sternotomy was used for combined procedures (20 patients). The SVC was cannulated well above the highest anomalous vein, which always entered below the azygos vein (Figure 1, A). A small high atriotomy was performed to confirm morphologic features and for placement of the retrograde cardioplegia cannula. The SVC was incised 2 to $3 \mathrm{~mm}$ behind the sinus node (Figure 1,B). The created flap was sutured to the caval wall and the rim of the ASD to create an unobstructed tunnel, routing the anomalous pulmonary veins to the ASD (Figure 1,C). A generous pericardial patch was harvested to reconstruct and augment the SVC (Figure 1, D). Suturing required that fine superficial bites be taken at the flap-pulmonary vein junction and stay in the endocardium behind the sinus node (Figure 1,E). All suture lines were performed with running 5-0, 6-0, or 7-0 monofilament sutures, depending on structure size and quality. 